
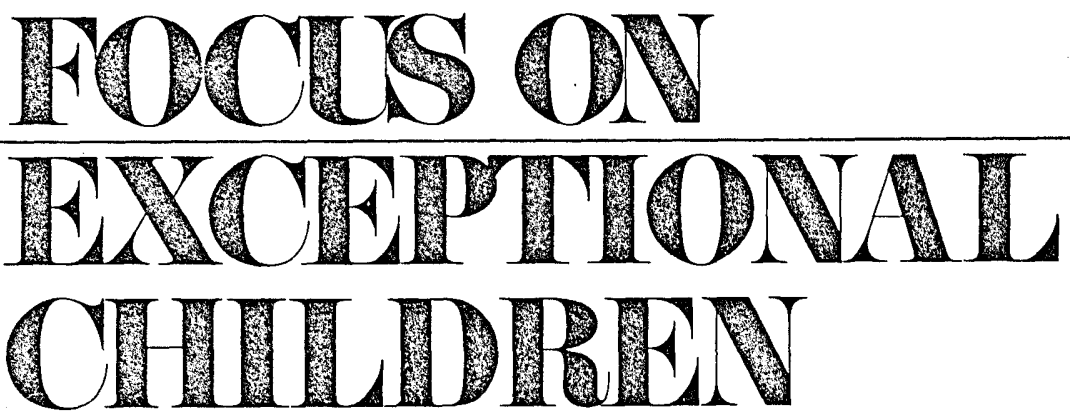

\title{
The Feuerstein Perspective On the Modification of Cognitive Performance
}

Robert Harth, Ed.D.

Education of exceptional children, particularly the mildly handicapped, is going through major changes. A new era of optimism is gradually taking hold. Feuerstein (1979) has brought this transition into perspective by describing the old and new approaches. The old approach, which he labels "passive-acceptant," is based on the assumption that low functioning individuals are not modifiable, that their present level of functioning is considered to be an adequate reflection of their potential. Educational programs based on this approach are primarily designed to prepare an individual to function at this low level. These programs mold the requirements and activities of the educational setting to fit the student's level of functioning. Thus, the student's educational program prepares him or her to function in a marginal, perhaps semi-dependent, environment.

The approach toward which we are moving is termed by Feuerstein as "activemodification." This approach looks at the exceptional individual as an open system, amenable to considerable modification under appropriate social, cultural, and educational policy. The observed low level of performance is accepted neither as status quo nor as a fixed ceiling of an individual's capacity. The emphasis with this approach is to move the individual toward increasingly higher levels of functioning.

Over the past 30 years, Feuerstein has been working toward the development of procedures to facilitate active-modification programs for exceptional students. This article will focus on four related topics. The first is the theory of Mediated Learning Experience, which is the theoretical base for Feuerstein's work. Second, we will look at the Learning Potential Assessment Device, Feuerstein's unique approach to the assessment of learning potential. Third, we will take a look at Feuerstein's curriculum for remediating cognitive deficits - Instrumental Enrichment. Finally, the article will discuss the implications of Feuerstein's work for the teaching of academic subjects.

Dr. Harth is Chairperson of the Department of Special Education, National College of Education, Evanston, Illinois.

๑ Love Publishing Company 1982 


\section{THEORY OF MEDIATED LEARNING EXPERIENCE}

Proper understanding of Dr. Feurstein's work requires a discussion of his theory of mediated learning experience (MLE). The theory argues that development of cognitive structures in an individual is a function of an organism interacting with the environment in two ways.

The first of these interactions involves direct exposure to sources of stimuli that impinge on the organism, starting from the earliest stages of its development. This mode of interaction is the more universal of the two since it tends to be characteristic of most living organisms. Exposure to sources of stimuli affects the organism behaviorally and cognitively. This, in turn, affects its interaction with the environment.

The second type of interaction is the mediated learning experience. MLE is much less universal and more characteristic of man. It refers to the way in which a mediating agent transforms stimuli emitted by the environment for the growing organism. The mediating agent, usually a parent, sibling, or other caregiver:

... guided by his intentions, culture and emotional investment, selects and organizes the world of stimuli for the child. The

FOCUS ON EXCEPTIONAL CHILDREN (ISSN 0015-511X) (USPS 203-360) is published monthly except June, July, and August as a service to teachers, special educators, curriculum specialists, administrators, and those concerned with the special education of exceptional children. This journal is abstracted and indexed in Exceptional Child Education Resources, and is also available in microform from Xerox University Microfilms, Ann Arbor, Michigan. Subscription rates, $\$ 15.00$ per year. Copyright 1982, Love Publishing Company. All rights reserved. Reproduction in whole or part without written permission is prohibited. Printed in the United States of America. Second class postage is paid at Denver, Colorado. POSTMASTER: Send address changes to:

Love Publishing Company

Executive and Editorial Office

1777 South Bellaire Street

Denver, Colorado 80222

Telephone (303) 757-2579

\section{EDITORIAL BOARD}

Edward L. Meyen

University of Kansas

Richard J. Whelan

University of Kansas Medical Center

Carolyn Acheson

Senior Editor

Stanley F. Love

Publisher mediator selects stimuli that are most appropriate and then frames, filters, and schedules them: he determines the appearance or disappearance of certain stimuli and ignores others. (Feuerstein, 1980, p. 16)

By this mediating process, a child acquires behavior patterns and learning sets that eventually make it easier for him or her to become modified by direct exposure to stimuli. This becomes, of course, an extremely important process for the developing child. Direct exposure to stimuli constitutes the greatest part of the organism's experience. Thus, the existence of behavior patterns and learning sets (acquired through mediation) allows the child to learn from direct exposure to stimuli. With mediation individuals are able to frame, filter, and schedule direct stimuli themselves.

The MLE theory requires us to look at alternative ways of conceptualizing the etiology of retarded cognitive performance. Feuerstein (1980) has distinguished between what he calls the "distal etiology" and the "proximal etiology." The distal etiology includes things we traditionally assume to be the causes of retarded cognitive performance - hereditary/genetic factors, organicity, reduced environmental stimuli, socioeconomic status, emotional problems of child/parents, and so on. Feuerstein argues that these are not necessarily the direct causes of retarded performance. Rather than

\section{STATEMENT OF OWNERSHIP, MANAGEMENT AND} CIRCULATION

Date of Filing: September 30, 1982

Title of Publication: FOCUS ON EXCEPTIONAL CHILDREN

Frequency of Issue: Monthly except June, July and August

Location of Known Office of Publication: 1777 S. Bellaire St., Denver, Co 80222

Location of Headquarters of Publisher: 1777 S. Bellaire St., Denver, CO 80222

Name and Address of Publisher, Editor, and Managing Editor: Stanley F. Love, 1777 S. Bellaire St., Denver, CO 80222

Owner: Stanley F. Love

Extent and Nature of Circulation:

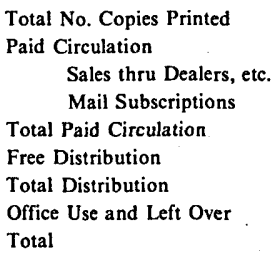

Average No. Copies
Each Issue during
Preceding 12 months

6,350

0
4,842

4,842

600

5,442

908
6,350
Single Issue Nearest to

Filing Date

5,000

0

4,256

4,256

600

4,856

5,000
I certify that the statements made by me above are correct and complete. 
FIGURE 1

\section{Deficient Cognitive Functions}

\section{Input Level}

1. Blurred and sweeping perception.

2. Unplanned, impulsive, and unsystematic exploratory behavior.

3. Lack of, or impaired, receptive verbal tools that affect discrimination.

4. Lack of, or impaired, spatial orientation.

5. Lack of, or impaired, temporal concepts.

6. Lack of, or impaired, conservation of constancies.

7. Lack of, or deficient, need for precision and accuracy in data gathering.

8. Lack of capacity for considering two or more sources of information at once; this is reflected in dealing with data in a piecemeal fashion, rather than as a unit of organized facts.

\section{Elaboration Level}

1. Inadequacy in the perception of the existence and definition of an actual problem.

2. Inability to select relevant vs. non-relevant cues in defining a problem.

3. Lack of spontaneous comparative behavior or limitation of its application by a restricted need system.

4. Narrowness of mental field.

5. Episodic grasp of reality.

6. Lack of, or impaired, need for pursuing logical evidence.
7. Lack of, or impaired, interiorization.

8. Lack of, or impaired, inferential-hypothetical thinking.

9. Lack of, or impaired, strategies for hypothesis testing.

10 Lack of, or impaired, ability to define the framework necessary for problem solving.

11. Lack of, or impaired, planning behavior.

12. Nonelaboration of certain cognitive categories, because the verbal concepts are not a part of the individual's verbal repertoire on a receptive level.

\section{Output Level}

1. Egocentric communication modalities.

2. Difficulty in projecting virtual relationships.

3. Blocking.

4. Trial-and-error responses.

5. Lack of, or impaired, tools for communicating adequately elaborated responses.

6. Lack of, or impaired, need for precision and accuracy in communicating one's responses.

7. Deficiency of visual transport.

8. Impulsive, acting out behavior.

Note: This figure represents only a listing of the deficient functions. Readers are encouraged to read Chapter 4 of Feuerstein's Instrumental Enrichment (Baltimore: University Park Press, 1980), pp. 71-105, for a more complete description of the deficient cognitive functions. triggering the retarded performance, they instead trigger the proximal etiology - a lack of MLE. The lack of MLE is directly responsible for the cognitive deficit, regardless of the nature of the distal etiology. The important notion here is that if we can apply appropriate mediated learning experiences that can overcome or bypass the factors preventing mediation (distal etiologies), we can restore normal cognitive growth.

A lack of MLE means that a child has not had the environment intentionally mediated to him or her. As a result, the child will not be modified by direct exposure to stimuli. He or she will have limited ability to become modified by life situations and exposure to new situations. The child is bound to fail because there is no way of relating an event to what has preceded or to what will follow. The impact of this will be felt most in areas requiring cognitive behavior (i.e., academic work in school).

The performance of individuals who have not received MLE is characterized by a deficiency in the cognitive functions considered to be prerequisites to operational, internalized representational thinking. Over many years of clinical experience, Feuerstein has identified a number of these deficient functions. Figure 1 represents a listing of the deficient functions identified thus far; the impaired deficient functions are categorized into the input, output, and elaboration levels. 
At the input level, the impaired cognitive functions represent the things that affect the quality and quantity of data gathering as an individual begins to solve a given problem. The elaboration level includes deficient functions that prevent individuals from making efficient use of the data available to them. At the output level are factors that lead to inadequate communication of the results of an elaborative process.

Although these levels overlap considerably, distinguishing between them is important for diagnostic and prescriptive purposes. Failure to do this often results in mistakenly identifying a cognitive deficiency as a problem of elaboration when it may actually be a problem of input or output.

Feuerstein considers input and output as peripheral determinants of the cognitive processes and elaboration as a more central determinant. Elaboration is more essential for appropriate cognitive functioning. Deficiencies of input or output do not impair the child as much as do elaborational deficiencies. Because of difficulties at the input and output level, we often fail to see that elaboration is intact. In many instances, the elaboration problems we see are nothing more than the result of faulty input or output.

Central to Feuerstein's work is his concept of modifiability. Feuerstein notes that the deficient functions are not fixed. The MLE theory proposes that these deficient functions are amenable to change, regardless of the individual's age or developmental level.

\section{THE LEARNING POTENTIAL ASSESSMENT DEVICE}

The functioning of retarded performing individuals represents a problem in trying to assess these individuals' true capacities. Most approaches to assessing capacity focus on manifest functioning; that is, a series of cognitive tasks are presented to an individual in a structured way, making assumptions about capacity based upon the performance. Feuerstein (1979) argues that in assessing retarded performing individuals, one must abandon the focus on manifest functioning. He advocates, instead, an approach that looks at modified performance. In this "modificational assessment" one controls the deficient functions (see Figure 1), then observes performance.

Feuerstein's approach to this type of assessment is his Learning Potential Assessment Device (LPAD). The LPAD has five purposes: (1) to assess general learning modifiability, (2) to assess the extent of modifiability, (3) to assess the amount of teaching investment necessary to bring about changes, (4) to assess the probability of transfer of new learning to other areas, and (5) to determine appropriate strategies to bring about change in the individual.

The LPAD is typically administered on an individual basis (although a group version has been developed as well). In its administration a student is taught a series of problem-solving strategies and then is asked to use those strategies on a series of new and more difficult tasks. Central to the assessment is the identification of deficient cognitive functions and, then, the control of them in the teaching process.

Because of the nature of this device, Feuerstein has introduced four major changes in testing procedure. The first of these is a change in the examiner-examinee relationship. With the LPAD, the examiner becomes a teacher and the examinee becomes a learner. The examiner teaches problem-solving strategies and helps the examinee apply them to increasingly difficult tasks. The examiner does not have a rigidly defined script to be used during administration. Rather, the examiner has a set of guidelines that define the parameters of the task. From this point on the examiner uses whatever strategies are available to assure that the individual learns the principles inherent in the task.

The second change is in the structure of the test. The test instruments are similar to appropriately graduated, well sequenced educational curricula.

Another important change is a shift from a product to a process orientation. In most traditional tests the product of a cognitive process is what is important. The examiner is interested in determining if the student can come up with the correct answer to a problem. The LPAD is not concerned with what the student knows. It is more concerned with how an individual learns - what he or she does and does not do when trying to solve a problem. Perhaps even more important than either of the above is whether the student can be induced to do something different and thus come up with a more appropriate product.

The final change has to do with interpretation of test results. The LPAD is less concerned with scores than are most traditional tests. It tends to be more interested in a description of how the child learns. The focus of a typical testing report is on a narrative of the deficient cognitive functions, functions that are not deficient, and the individual's response to modification procedures. 
The LPAD, then, involves a teach-test procedure. The child is taught a number of problem-solving strategies and then is tested to determine the extent to which he or she can become modified by instruction. Upon completion of the testing, several kinds of data are available. First, data is available on the extent of modifiability. Did the student learn? Did the student systematically apply what was taught? Related to the above is the issue of amount of investment. This is important not only to determine whether or not the student learned but also to determine how much instructional effort was necessary to produce successful learning. A third type of data available after testing is a description of the child's unique pattern of deficient functions. The examiner can identify these functions and describe how they impacted on the student's learning. After the assessment the examiner has a notion of the types of approaches to instruction that proved most useful.

\section{INSTRUMENTAL ENRICHMENT}

To remediate the deficient cognitive functions Feuerstein (1980) has developed a specific curriculum called Instrumental Enrichment. The aim of the program, as described by Feuerstein, is to:

\section{... change the overall cognitive structure of the retarded performer by transforming his passive and dependent cognitive style into the characteristic of an autonomous and independent thinker. (Feuerstein, 1980, p. 1)}

The specific goals and objectives of Instrumental Enrichment are presented in Figure 2.

\section{FIGURE 2}

\section{Goals and Objectives of Instrumental Enrichment}

Major Goal: To increase the capacity of the human organism to become modified through direct exposure to stimuli and experiences provided by encounters with life events and with formal and informal learning opportunities.

\section{Major Subgoals:}

1. The foremost subgoal is correction of the deficient cognitive functions.

2. Acquisition of basic concepts, labels, vocabulary, operations, and relationships necessary for instrumental enrichment.
3. Production of intrinsic motivation through habit formation.

4. Production of reflective, insightful processes in the student as a result of his confrontation with both his failing and succeeding behaviors.

5. Creation of task-intrinsic motivation.

6. A shift from the role of a passive recipient and reproducer of information to the role of a generator of information.

Note: From Feuerstein's Instrumental Enrichment (Baltimore, MD: University Park Press, 1980).

Instrumental Enrichment is a paper-and-pencil curriculum administered three to five times a week over a two- to three-year period. Each lesson lasts about one hour and is typically used as part of the school program. The more than 500 pages of exercises are divided into 15 instruments. Each instrument focuses on a specific deficient cognitive function but addresses other cognitive functions as well. When typically applied as part of a large school program, it is taught to whole-class groups in a prescribed sequence. For prescriptive remedial purposes a clinician may select particular instruments to match the deficient functions of the pupil under treatment.

Each of the instruments is content-free; it does not address any specific curricular skill or content area. Rather, it focuses on the process of learning directly. The content around which the instruments are built serve only as vehicles for development of the prerequisites of thinking.

Perhaps the best way to express the nature of the program is to describe the IE lesson. Although teacher's manuals are available, each lesson does not have a script. The teacher has to clearly define the objectives and scope of each lesson based upon the needs of the particular group of students. The manual gives guidelines and suggestions.

The lesson begins with an introductory discussion lasting about 10 minutes. The purpose is to define the problem in the lesson and to stimulate interest and motivation. As much as possible, definition of the problem is drawn from the students rather than being presented by the teacher.

The introductory discussion is followed by about 25 minutes of independent activity in which the students 
work on the problem. During this time the teacher circulates around the room offering individualized assistance, reinforcing successful mastery of the task, and preventing frustration or repetition of errors.

The independent work leads into a discussion and insight development period that lasts about 10 minutes. In this period the teacher and the students explore various thought processes and alternative responses used in the activity. Also, difficulties that were faced are analyzed, as well as ways in which the difficulties were overcome. An important element of this phase of the lesson is what Feuerstein calls "bridging." In bridging, the principles and processes learned are discussed in terms of their relevance to the real world. This, of course, becomes a critical determinant of generalization and transfer.

The lesson ends with a five-minute summary including a review of the lesson and an assessment of the degree to which the goals were achieved. When first using IE, the teacher does the summary. Later, this becomes the students' responsibility.

\section{APPLICATION TO THE TEACHING OF ACADEMICS}

As indicated earlier, typical application of the Feuerstein model is through Instrumental Enrichment. The procedures to be discussed were developed by the author (Harth, 1981) in two special education classes in Sedalia, Missouri.

Feuerstein is skeptical about the use of curricular content learning for enhancing and modifying cognitive performance. In fact, he has identified a number of problems associated with this (Feuerstein, 1980, pp. 120133). The first has to do with the nature of disabled learners who tend to be action-oriented and unwilling to operate beyond the solution of content activities. Once the problem is solved, students like this are unwilling to enter into a discussion of the material or into an analysis of its various components and the relationship existing between them. The second set of problems relates to the nature of content material itself. Curricular content has its own structure and sequence that do not always coincide with that needed for producing cognitive changes. A third problem relates to the teacher. Teachers tend to not be trained in the area of recognizing prerequisites of cognitive behavior. Consequently, they have difficulty recognizing cognitive deficiencies when they occur. Finally, Feuerstein is concerned about previous failure. Most of these children have histories of failure with curriculum content, which produces resistance to full involvement.

These problems identified by Feuerstein certainly make the challenge of producing cognitive changes more difficult if one is to use curricular content materials. Even so, it was felt that if one were to use Instrumental Enrichment, change could be facilitated if similar procedures for teaching could be used for dealing with academics.

In applying the Feuerstein model to teaching curriculum content, the Learning Potential Assessment Device proved quite useful. This is because the LPAD offers a structured approach for teaching cognitive material. Through this approach one is able to respond to the deficient cognitive functions, as well as to other aspects of cognitive problem solving. Teaching in the LPAD is directed not only at teaching specific content, but it also tries to establish the prerequisites to cognitive functioning and the necessary behaviors for problem solving.

In translating the LPAD approach to classroom teaching, one major adjustment must be made. The LPAD is an individually administered device. The examiner, who is always in contact with the student, can adjust the teaching and respond directly to each student's specific needs. In classroom teaching, teachers tend to deal with groups of students. As a result, they are not always in direct one-to-one contact with students. This requires the introduction of mediation directly into the written assignments presented to the students. (This will be discussed more fully later in the article.)

Feuerstein (1979) has described five aspects of the teaching process in the LPAD: (1) regulation of behavior through inhibition and control of impulsivity, (2) improvement of deficient cognitive functions, (3) enrichment of the repertoire of mental operations, (4) enrichment of the task-related contentual repertoire, and (5) creation of reflective, insightful thought processes. These five points also form the basis for teaching academics under the Feuerstein model.

\section{Regulation of Behavior through Inhibition and Control of Impulsivity}

This deficient cognitive function tends to be a major problem with many retarded performing students. It is 
the most frequently noted of the deficient functions, and the first to which a teaching response is required. This impulsivity, seen at the input, elaboration, and output levels, is a major source of errors in the problem-solving behavior of these students. One of the major ways of controlling impulsivity is for the teacher to impose a latency in responding.

An example of this procedure occurred in the work in Sedalia. In a group lesson the teacher would ask a question and the students would immediately blurt out answers. To initially counter this, the teacher required the students to write out their answers before orally responding. This imposed a time lapse between presentation of the problem and discussion of the response. The result was a tendency to reduce some of the impulsivity and increase more thoughtful behavior.

When some control of impulsivity through this procedure was observed, the teacher began to phase out the procedure and to introduce the use of cue words to regulate behavior. After asking a question, the teacher would initially say "stop," then "think," then "raise your hand." These words were eventually put on a sign in the classroom and the teachers would point to them at appropriate times.

\section{Improvement of Deficient Cognitive Functions}

The second aspect of the teaching process involves improvement of deficient cognitive functions. Impulsivity is not the only deficient function seen in retarded performing students. Each student has a unique pattern of deficient functions.

Deficient functioning tends to be a far greater problem when the students are working by themselves. Without the teacher's constant vigilance, problem-solving behavior tends to break down. In this situation a whole complex of deficient functions commonly begin to show up. This complex can be defined by the following deficient functions.

\section{At the Input Level}

1. Blurred and sweeping perception.

2. Unplanned, impulsive, and unsystematic exploratory behavior.

\section{At the Elaboration Level}

3. Inadequacy in the perception of the existence and definition of an actual problem.

4. Inability to select relevant versus non-relevant cues in defining a problem.

5. Lack of, or impaired, ability to define the framework necessary for problem solving.

6. Lack of, or impaired, planning behavior.

\section{At the Output Level}

7. Trial-and-error responses.

8. Impulsive, acting-out behavior.

The result of all of this is that the student presents a disorganized approach to the task, reflecting a lack of investment in the task. To counter this kind of problem solving, a rather elaborate procedure must be applied to the variety of independent seatwork activities presented to the students. Figure 3 gives an example of one way in which this problem can be handled. The example comes out of the work in Sedalia mentioned earlier.

\section{FIGURE 3 \\ Examples of Traditional and Modified Assignment \\ WRITING TITLES (Traditional)}

Titles of complete books are usually underlined when handwritten. Titles of parts of books (chapters, songs, poems, stories) are usually in quotation marks. All important words are capitalized. Use capitals where needed. Underline or put titles in quotes.

1. Mark Twain wrote the book tom sawyer.

2. Who wrote the song the star-spangled banner?

3. . ...............................

\section{WRITING TITLES (Modified)}

Titles of complete books are usually underlined when handwritten. Titles of parts of books (chapters, songs, poems, stories) are usually in quotation marks. All important words are capitalized. Use 
capitals where needed. Underline or put titles in quotes.

1. Mark Twain wrote the book tom sawyer.

A. Find the title.

B. Will you underline it or put quotation marks around it?

C. What words will you capitalize?

2. Who wrote the song the star-spangled banner?

A. Find the title.

B. Will you underline it or put quotation marks around it?

C. What words will you capitalize?

3.

Note: See R. Harth, R. Johns, C. Cloud, \& C. Campbell, "Mediation: How it can improve problem solving skills" Academic Therapy, 1981, 17, 225-230.

In the figure, two versions of a seatwork assignment are presented. The first is the assignment in its traditional form. This is usually presented to a group of students following an introductory activity introducing the task. The second is the modified version designed to control the complex of deficient functions identified earlier. The modified version contains two sets of directions. The first set consists of instructions typically included on the top of the page. The second set is written specifically for each item on the worksheet. These appear below each item.

Data were collected on the use of this particular assignment to determine if it would promote better performance. The traditional assignment was given on one day, followed by the modified assignment on the next day. Two days later the students were given the traditional assignment again, this time with new sentences. Each assignment had 20 sentences. The results, shown in Table 1, clearly reveal that the strategy was effective in helping the students increase their effectiveness on those assignments.

These are not the only deficient functions seen in retarded performing students. A lack of spontaneous comparative behavior tends to be a rather common deficiency. In most cases, these students can compare, but they do not do so spontaneously. The curriculum is rich in possibilities for using comparative behavior. Science, social studies, current events, math, and so on all provide opportunities for comparison. The teachers should make sure that comparative behavior is required.
Lack of planning behavior, a deficient function identified earlier, also tends to create problems. Often, students jump into a task without planning ahead of time what they are going to do. A number of activities can facilitate planning behavior. Before starting a task the teacher must assist the students in identifying their plan of attack. One useful activity is to have students plan out their day when they arrive in school. The teacher can start by just assisting them in planning the school day. Eventually, this can extend to planning after-school and evening activities - which is much more complicated because more choices are available; students have to balance things such as play, chores, eating, and television in their plans.

The above are only a few examples of the kinds of activities that can be done in response to deficient functions. In the project in Sedalia, these and other strategies were generated through a process of observing poor problem solving, identifying the deficient function, and brainstorming strategies that might control the behavior. These strategies were tested and their impact was determined. The example presented earlier, "Writing Titles," was derived from this process.

Two additional issues require discussion. The first has to do with the permanence of changes produced. Retarded performers have developed a number of ineffective approaches to problem solving. The procedures

\section{TABLE 1}

Percentage of Correct Responses on Each of the Three Assignments

\begin{tabular}{ccrc}
\hline Student & Traditional & Modified & $\begin{array}{c}\text { Follow-up } \\
\text { (Traditional) }\end{array}$ \\
\hline & $(\%)$ & $(\%)$ & $(\%)$ \\
A & 37 & 88 & 87 \\
B & 52 & 91 & 89 \\
C & 42 & 100 & 81 \\
D & 35 & 80 & 88 \\
E & 32 & 100 & 87 \\
F & 63 & 83 & 94 \\
G & 84 & 88 & 90 \\
\hline
\end{tabular}

defined above should facilitate a change. For the change to be meaningful, however, it has to become habitual. The student has to use the approach regularly without a need for teacher reminders. The only way this will occur is if the teacher consistently requires the use of appropriate strategies over time. For instance, planning be- 
havior will become habitual only if the teacher constantly requires the student to plan.

The second issue is independence. The techniques described above are, for the most part, imposed by a teacher on a student. For example, in the task "Writing Titles," the teacher essentially imposed an effective problem-solving structure on the students. This has to be seen as only a starting point. Eventually the students need to be able to impose their own structure on a task. This issue, and procedures for addressing it, are discussed in the section, "The Creation of Reflective, Insightful Thought Processes."

\section{Enrichment of the Repertoire of Mental Operations}

The third aspect of the teaching process involves enrichment of the student's repertoire of mental operations. By including this as part of the teaching process, Feuerstein (1979) is saying that the LPAD responds not only to the deficient functions but also tries to enrich the student's mental operations. Here, use of the Feuerstein model to teach content differs from teaching in both the LPAD and in Instrumental Enrichment. In both the LPAD and Instrumental Enrichment, the appearance of mental operations such as analogies, categorization, progressions, seriation, and so on are highly structured. They appear in systematic ways and can be dealt with in systematic ways. When the medium of intervention is curriculum content, the appearance of these operations is not as structured. Curriculum content has its own structure, and we can respond to the operations only when they occur. This is not to say that one cannot respond to the mental operations, but the intensity of response will not be at the same level as with the LPAD or with Instrumental Enrichment. This is a strong argument for the combined use of Instrumental Enrichment and these content teaching procedures.

\section{Enrichment of the Task-Related Contentual Repertoire}

The next aspect of the teaching process is enrichment of the task-related contentual repertoire. Essentially, what Feuerstein is talking about is that certain concepts must be present for efficient problem solving to take place. Specifically, such content can be grouped into three categories.

The first category is made up of orientation concepts. This refers to things such as left, right, up, down, before, after, vertical, horizontal, and so forth. The second category is formed by concepts dealing with relationships between objects and events. These include concepts such as identical, opposite, common, similar, different. For any type of relational thinking, these concepts are required. The final category involves labels for specific objects or events and their characteristics. This includes not only the ability to label but to describe characteristics as well.

Without sufficient background in these three areas, students have tremendous difficulty in solving curricular problems. It means that the teacher must be checking constantly to see that these concepts are accessible to the student and be prepared to provide specific instruction if they are not.

\section{Creation of Reflective, Insightful Thought Processes}

Perhaps the most important aspect of the teaching process is the creation of reflective, insightful thought processes. Insight is defined as an awareness of one's own problem-solving behaviors. It is essential for generalization and transfer, particularly for processes that are newly learned and, therefore, vulnerable. Throughout teaching, the teacher continually strives to provoke reflective thinking in the student.

Reflective thinking is encouraged by having students analyze behaviors that have led to a given outcome, whether that outcome was a success or a failure. When confronted with failure, the individual should be able to isolate the particular causes, and even relate them to the deficient functions - for instance, "I got the problem wrong because I didn't look at the whole problem" (blurred and sweeping perception). When the student is successful, he/she should be able to do the same thing.

Reflective, insightful thinking is also facilitated by having students identify the process they used to solve a particular problem. Initially, the teacher may identify the process for them, but eventually they must identify the process for themselves. Figure 4 presents an example of an arithmetic assignment in which the process is presented to the student. Figure 5 gives an example of an assignment in which the student must identify the process himself/herself.

Some additional techniques for creating reflective, insightful thought are:

1. Questioning reasons for responses.

2. Discussing how the correct answer was attained.

3. Comparing present performance with how a student used to approach similar problems.

4. Discussing systematic ways to approach a problem. 


\section{FIGURE 4}

Worksheet With Process Written Out

\section{Math - Reducing Fractions}

1. Write all of the factors.

2. Write all of the common factors.

3. Circle the largest common factor.

4. Divide by the largest common factor.

Example: $3 / 6=\left.\frac{1 / 2}{\left.\right|_{N}}\right|_{N} ^{N}$

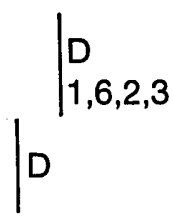

\begin{tabular}{|l|l}
$\begin{array}{c}\text { Common factors } \\
1,3\end{array}$ & $\begin{array}{l}\text { Divide } \\
3 / 6 \div 3=1 / 2\end{array}$ \\
common factors & Divide
\end{tabular}

1. $2 / 4=$

2. $3 / 9=$

3. $2 / 10=$

4. $6 / 8=$

5. $6 / 12=$

6. $4 / 12=$

FIGURE 5

Worksheet for Identifying the Process

Math

1. Work the problem

$24-4 / 5$

$+17-1 / 2$

2. Write the process

1.

2.

3.

4.

5.

6.

7.

8.

9.

10.

11.

12.

13.

14. 


\section{FIGURE 6}

\section{Excerpts from a Worksheet Requiring Reflective, Insightful Teaching}

Reading the Newspaper

Page Two

Find the headline, "Officials Say Chapman Planned Slaying."

Circle paragraphs one through five.

1. Who was John Lennon? (tell two things about him)
A. Read the question.
B. Circle the key words.
C. Find the key words on the board.
D. Think about the discussion.

4. What do most killers do after they shoot someone?
A. Read the question.
B. Circle the key words.
C. Think.
D. What would you do?

5. Why do you think Chapman did what he did after killing Lennon?
A. Read the question.
B. Circle the key words.
C. Think.
D. Why would he just sit down?

7. How many months had Chapman been working for Liva?
A. Read the question.
B. Circle the key words.
C. Find the key words in the article.
D. Think. You will have to do a little math. 
5. Questioning and discussing sources of error.

6. Distinguishing between correct and incorrect parts of answers.

7. Generating similar examples for generalization.

The creation of reflective, insightful thinking is directed not only at the problem-solving process but also the curriculum content itself. In teaching, the concern is not only with the correct answer but also with having students think about their work. Teacher questioning must go beyond the "right" answer. Students must be asked to do a number of things: to speculate about implications of certain events, to discuss the application of information learned in various subject areas, to project the meaning of events into the future. Students must be asked what they think led to a certain event - i.e., what may have caused something to happen. In summary, students are asked to put themselves into situations that arise in the content of the curriculum.

Figure 6 represents an excerpt from a worksheet designed to encourage reflective, insightful thinking. The worksheet is from a lesson used in the project in Sedalia. Some of the items on the worksheet are simple, direct questions that require nothing more than finding the answer in the newspaper. Items 5,6 , and 10 , however, can be answered only by reflection and insight. The figure contains one of these, Item 5 .

\section{Mediated Learning Experience}

The previous sections of this article have essentially defined a mediated learning experience approach to teaching curriculum content. Before leaving this topic, the three major criteria for this approach to teaching (Feuerstein, 1980) are briefly discussed below.

The first criterion is intentionality. Mediation is an intentional act in which both teacher and student are aware of what is happening. When the teacher, for instance, points out a sequence of events to the student, it is done intentionally to convey to the student the idea that it is important. Thus, this criterion creates in the student the appropriate orientation to the task, the readiness to attend to the task, and the ability to focus and persevere.

The second criterion is transcendence. With any instructional interaction the teacher is trying to do at least two things. First, of course, the teacher is trying to teach the particular task. But the teacher should be doing more than that. The teacher should also be teaching strategies that transcend the immediate task. He/she should be developing skills that are useful not only for the immediate task, but that can be used in solving other problems as well. In controlling the deficient functions, in sensitizing the student to the process, the teacher is transcending the immediate task. Transcendent goals determine the nature of intervention in a mediated learning experience. This second criterion - transcendence - allows the student to use the acquired principles, rules, and functions for more remote types of tasks. This becomes a major factor in the generalization and transfer of learning.

The third criterion of mediated learning experience is the mediation of meaning. Performance on a task should be a response to a need. One of the characteristics of retarded performing students is that they are not motivated to perform cognitive tasks. As a result, the teacher must create and reinforce the need for performance. To the extent that the teacher is successful here, the student's need system will be enlarged and the potential for higher levels of motivation and achievement need will be created.

\section{SUMMARY AND CONCLUSIONS}

A mediated learning experience approach offers possibilities for the education of retarded performing students. An approach to assessment and two instructional approaches were discussed in this article. The question at this point is whether one should use both approaches to instruction or whether one will suffice.

Instrumental enrichment, as it is traditionally taught, pays little attention to the teaching of content. Similarly, content approaches most often do not attend to the cognitive processes. Instrumental enrichment, combined with the kinds of content teaching procedures identified in this paper, appear to offer the best chance for producing the most in the way of cognitive redevelopment. Both make unique contributions to the other. This is not to say that one, by itself, will not produce change but that combined, the possibility of change is expanded.

\section{REFERENCES}

Feuerstein, R. The dynamic assessment of retarded performers. Baltimore, MD: University Park Press, 1979.

Feuerstein, R. Instrumental enrichment. Baltimore, MD: University Park Press, 1980.

Harth, R. The Sedalia project. Unpublished manuscript, 1981.

Harth, R., Johns, R., Cloud, C., \& Campbell, C. Mediation: How it can improve problem solving skills. Academic Therapy, 1981, 17, 225-230. 